Artigo

\title{
Política Imigratoria Espanhola entre 1945-1960: o caso gallego
}

Spanish Immigration Policy (1945-1960): The galician case

Política Emigratoria Española entre 1945-1960: el caso gallego

Xosé Ramón Campos Álvarez¹.

\footnotetext{
${ }^{1}$ Filiação institucional. Licenciado em Geografia e História pela Universidade de Vigo, Espanha, e doutor em História da América pela Universidad Complutense de Madrid, Espanha. Atualmente é professor da área de História da América da Universidade de Vigo, Ourense, Espanha.

Correspondência: E-mail: xrcampos@uvigo.es
}

Resumo No presente artigo realiza-se uma aproximação à política emigratória espanhola durante os primeiros anos do franquismo e suas repercussões em Galiza. Uma vez finalizado - grande ciclo emigratório americano em 1930, este se volta a recuperar a partir de 1946 impulsionado pela abertura da política migratória e se consolida na década dos cinquenta. Também se trata de refletir o contexto histórico no que tem lugar este processo, fazendo especial finca-pé na situação socioeconómica da Galiza das décadas dos 40 e 50.

Palavras-chaves: Emigração; Espanha; Franquismo; Política Emigratória; Galiza.

Abstract The present article describes the approximation of the Spanish emigration politic during the first years of Franco and their impacts in Galicia. After finishing the big American migration cycle in 1930, they started to drive the political migration since 1946 and strengthen it in the following $50^{\text {th }}$ decade. Besides the article reflected the historical context in which this process has taken place and pointed out specially the socioeconomic situation of Galicia in the $40^{\text {th }}$ and $50^{\text {th }}$ decade.

Keywords: Emigration; Spain; Franco; Emigration Politic; Galicia. 
Resumen En el presente artículo se realiza una aproximación a la política emigratoria española durante los primeros años del franquismo y sus repercusiones en Galicia. Una vez finalizado el gran ciclo emigratorio americano en 1930, este se vuelve a recuperar a partir de 1946 impulsado por la apertura de la política migratoria y se consolida en la década de los cincuenta. También se trata de reflejar el contexto histórico en el que tiene lugar este proceso, haciendo especial hincapié en la situación socioeconómica de la Galicia de las décadas del 40 y 50.

Palabras Clave: Emigración; España; Franquismo; Política Emigratoria; Galicia. 


\section{Política emigratoria española 1945-1960. El caso Gallego}

Emigrar fue la solución escogida por miles de personas durante la historia reciente de España para tratar de mejorar su situación económica fuera de la tierra de origen. El constante goteo de migrantes hacia otros países, principalmente latinoamericanos, convirtió la emigración a principios del siglo XX en uno de los mayores agentes movilizadores de seres humanos, alcanzando entre los años 1905-1913 el millón y medio de personas (Kreienbrink, 2009: 14). La Primera Guerra Mundial supuso una limitación de los flujos migratorios, que, sin embargo, continuaron desarrollándose durante los años veinte a un ritmo acelerado, hasta que la crisis económica de 1929 y las restricciones impuestas por los países americanos hicieron que éstos fueran descendiendo paulatinamente hasta el inicio de la Guerra Civil Española. Durante la guerra, la inmediata posguerra y la Segunda Guerra Mundial, la emigración se paralizó casi por completo y no se reanudó hasta finalizada esta última.

Durante los años siguientes a la Segunda Guerra Mundial y en la década de los cincuenta, la emigración española transoceánica conoció un nuevo auge como consecuencia del cambio de política del gobierno franquista sobre la salida de españoles del país, la expansión económica experimentada en diversos países de América Latina y la necesidad de fuerza de trabajo inmigrante especializada (Palazón, 1995b: 185), además de la creencia oficial de que España padecía una alta presión demográfica y la emigración era la solución ideal al problema. Por otra parte, también permitía al país desembarazarse “de descontentos e inadaptados, a la vez que alimentaba los sueños del Imperio y daba alas a la política de la Hispanidad" (Gambi Giménez, 2012: 67).

Nuestra presencia en América es indispensable para la más recta solución de los trágicos problemas políticos y sociales del mundo presente, y por ello hay que aceptar la emigración hacia estos países, desviándola incluso de otros más cercanos en los que, por cierto no somos tratados con el debido respeto y cariño, y que no encierran interés racial para los españoles (González-Rothvoss, 1949: 71-72).

La política migratoria que llevó a cabo el franquismo se valió en un principio del corpus legislativo vigente en las décadas anteriores. Las restricciones existentes a la hora de emigrar durante la segunda mitad del siglo XIX y primeros años del XX se fueron eliminando poco a poco, a la vez que se gestaba la primera normativa sobre emigración.

El marco legal por el cual debían regirse las migraciones no se definió hasta el 21 de diciembre de 1907, cuando Alfonso Xlll sancionó una Ley que regulaba la dinámica de los movimientos migratorios de la población española. Con ella, se reglamentaba por primera vez "la libertad de todo español para emigrar" (Fernández Morales, 1992: 220). Su objetivo era proteger a los emigrantes en la preparación y realización de la travesía y constituía toda una novedad después de tantos años de restricciones por parte de la administración, regulando además, las actividades de los agentes encargados del viaje. 
Así, los temas referentes a la emigración pasaron a depender del Ministerio de la Gobernación, con un Consejo Superior -encargado de velar por la aplicación de la Ley de Emigración y su Reglamento- y un Negociado de emigración -órgano administrativo del Consejo Superior-. Además, la ley destinó a diferentes inspectores -en las regiones de mayor emigración, en los puertos de embarque, en los barcos y en los lugares de llegada- para que se encargaran de verificar, en los puntos más vulnerables del proceso migratorio, que se cumplían todos los requisitos para llevar a cabo el viaje.

Una novedad importante de esta Ley es la reglamentación de las condiciones que debía reunir cada barco para poder realizar el transporte de emigrantes, ya que en aquellos tiempos eran muy habituales las noticias acerca de las malas condiciones de las naves y de la travesía en general (escasez y mala calidad de las comidas, literas en malas condiciones, hacinamiento, etc.). Además, también establecía los requisitos que debían reunir las navieras y los consignatarios para que se les diera autorización para transportar emigrantes. Estas disposiciones eran respuesta a las numerosas noticias sobre engaños y abusos relacionados con las personas encargadas de tramitar y realizar el transporte de los emigrantes a los países de destino y con las agencias que se encargaban de gestionar la documentación necesaria para poder salir del país.

En este sentido, para mayor protección del emigrante se creó una Caja de Emigración - similar a lo que se llamará a partir de la Ley de 1924 el Tesoro del Emigrante - que se ocupaba de financiar los gastos que generaba el servicio a los emigrantes. Estaba constituida por dinero procedente de multas por infracciones, ingresos de publicaciones, donativos, subvenciones, etc. y con él se sufragaban los gastos del material y del personal encargados de todo el servicio y los gastos a mayores que pudiera conllevar la aplicación de la normativa.

Esta primera Ley de Emigración fue poco eficiente y con la llegada de la dictadura de Primo de Rivera se intensificaron los controles sobre los movimientos migratorios, por lo que dicha Ley, que ya había sido objeto de numerosas reformas con el fin de ampliar y mejorar sus competencias en materia de protección y control de los emigrantes, fue refundida en 1924 en una nueva, la Ley y Reglamento de Emigración.

El 16 de septiembre de 1924 se aprobaba un Real Decreto que establecía que todo lo referente a la emigración pasaba a depender del Ministerio de Trabajo, Comercio e Industria, en el que se creaba la Dirección General de Emigración (DGE). Este organismo fue el encargado de redactar las nuevas disposiciones para emigrar, proteger y tutelar a los emigrantes españoles, hasta la creación en 1956 del Instituto Español de Emigración (IEE).

La nueva normativa presenta una estructura similar a su predecesora, pero entre ambas existen diferencias notables. Primeramente, ambas leyes tratan "la libertad de todo español para emigrar", pero en la Ley de 1924 aparece ampliado este apartado. No sólo se trata la emigración individual, sino que ya se 
contempla la emigración familiar. En segundo lugar, se amplían las causas que motivan al emigrante a abandonar su país; y, por último, se diferencian dos formas de emigración hoy ya aceptadas: la emigración temporal y la emigración definitiva.

Además de estas variaciones, el nuevo texto establece cuatro prohibiciones a la hora de emigrar: 1a , los menores de edad o los declarados incapaces sin la compañía o autorización escrita del padre, de la madre o del tutor, o, en su caso, sin permiso del Patronato Nacional de Protección de Menores o del organismo competente; $2^{a}$, la mujer, cuando a ello se oponga alguna disposición legal reguladora de su capacidad civil o protectora de su sexo; 3a , los reclutas en Caja y los individuos en primera situación del servicio militar activo, salvo disposición en contrario de la correspondiente autoridad; 4a , los sujetos a procedimiento o condena penal (Fernández Morales, 1992: 222-223).

El cumplimiento de la ley era vigilado por los Inspectores de Emigración, localizados, al igual que en la legislación anterior, en los lugares donde se registraba un mayor número de desplazamientos. Entre sus tareas estaba controlar el cumplimiento de los contratos de emigración y las condiciones de los barcos -que se suponía habían mejorado con respecto a épocas anteriores-.

Uno de los instrumentos más importantes que se creó con esta ley fue el denominado Tesoro del Emigrante, considerado como una innovación de la Caja del Emigrante. Este fondo recogía el dinero proveniente de las multas a las navieras por infracciones de la ley; el importe de las patentes de consignatarios y oficinas de información; la recaudación de las publicaciones de la DGE, etc. Los gastos que se atendieran a través de este fondo debían ser notificados anualmente a la DGE y aprobados en una Junta Central. Como gastos estaban considerados los seguros y socorros de los emigrantes, las asociaciones y sociedades patrióticas, cualquier institución española asentada en los países de acogida de emigrantes que tuviera como cometido ayudar al emigrado en caso de necesitarlo, etc..

Durante la dictadura de Primo de Rivera y la II República se mantuvo esta última ley en vigor sin apenas modificaciones, ya que cada vez menguaban más las cifras de emigrantes debido a la crisis económica de final de los años veinte y cuando parecía que se volvía a reanudar el ciclo migratorio, la llegada de la Guerra Civil Española acabó por paralizarlo.

Unos meses antes del comienzo de la contienda, el Ministerio de Trabajo publicó el Decreto de 9 de mayo de 1936; en él se introducían mejoras en las condiciones de transporte de los emigrantes, aumentándose el personal español que los atendía a bordo de buques extranjeros (Fernández Morales, 1992: 226).

En 1938 se crearon los primeros ministerios en la zona franquista. El Ministerio de Trabajo fue sustituido por el Ministerio de Organización y Acción Sindical (MOAS), asumiendo éste las competencias laborales y sindicales. Uno de 
los servicios que pasó a desempeñar el MOAS fue el relativo a la emigración a través del Servicio Nacional de Emigración. Sus funciones terminaron una vez finalizada la guerra, pasando de nuevo al Ministerio de Trabajo la competencia en las migraciones (Fernández Vicente, 2009: 39).

Terminada la guerra e iniciado el franquismo, éste se vio en una difícil posición. La agricultura se había estancado, el poco desarrollo industrial se paralizó a consecuencia de la guerra y la represión una vez finalizada la contienda agravó la situación. La normativa que dirigía la emigración hasta ese momento seguía siendo la Ley de 1924, de tendencia liberal. En 1950 se volvió a superar la cifra de 50.000 personas que abandonaban España con destino a ultramar, preferentemente. Entre los años 1946 y 1960 abandonaron el territorio nacional 634.667 personas, según cifras oficiales ${ }^{1}$.

Además, a consecuencia de la Guerra Civil española, se inició una escasa, pero importante corriente migratoria compuesta por los exiliados, que escapados a Francia o Portugal, luego se trasladaban a Latinoamérica². Su importancia era capital, debido a que sus ideales políticos podían "contaminar" al resto de emigrados. Vista la situación, el gobierno franquista se vio en la obligación de promulgar el importante Decreto de 1 de agosto de 1941, referido a la Repatriación, Bonos, Acción Social y Consejo Central de Emigración (Kreienbrink, 2009: 15).

Con él, el Estado pretende regular los flujos migratorios y crear nuevos métodos para reintegrar a los emigrantes a "la Patria de aquellos de sus hijos que, lejos de ella, ansían su colaboración personal en la hora difícil y feliz de su engrandecimiento". En otras palabras, se pretende facilitar la repatriación de aquellos emigrantes que así lo deseen atendiendo a las necesidades de cada uno de ellos (Fernández Morales, 1992: 229).

Los objetivos demográficos del gobierno eran los responsables de este decreto. Su ideal autárquico en política económica pretendía incrementar la población española de 26 a 40 millones, por lo que las repatriaciones eran su principal meta. Para llevarlas a cabo, el citado decreto estipulaba cómo se obtendrían los fondos destinados al Tesoro del Emigrante y, a partir de los cuales, el Estado podía iniciar el proceso de repatriación. Así, los pasajeros extranjeros en buques que salieran para América desde cualquier puerto español, tendrían que abonar con el precio del billete el $2 \%$ de su total en divisas extranjeras. Estos fondos serían puestos a disposición de las autoridades pertinentes para ayudar al Estado en cualquier fase del proceso de repatriación (Fernández Morales, 1992: 232-233).

\footnotetext{
${ }^{1}$ Estadísticas de Emigración (años 1946 a 1960), Ministerio de Trabajo (elaboración propia).

2 Kreienbrink da la cifra de más de 20.000 personas para el periodo 1939-1945 (Kreienbrink, 2009: 15).
} 
Hasta 1946 estuvo vigente este Decreto de 1941. La imposibilidad por parte del gobierno de frenar el afán migratorio de la población llevó a éste a levantar la prohibición, aunque no de forma total, pues la abolición del citado decreto supondría volver a los preceptos de la normativa de 1924, por lo que el gobierno se cuidó de mantener para sí ciertas disposiciones restrictivas.

Desde octubre de 1935 -en un contexto de extrema conflictividad social-, el Ministerio de Trabajo tuvo que delegar en la Dirección General de Seguridad (DGS) la expedición de pasaportes, pasando esta última a controlar las entradas y salidas del país (Kreienbrink, 2009: 16). Por tanto, las competencias en materia migratoria permanecieron durante largos años bajo la tutela de la DGS, ya que el estado policial que se impondría durante el Régimen franquista identificaba la emigración con el exilio, debido a lo cual se explican las continuas negaciones de traspaso de competencias al Ministerio de Trabajo (Fernández Vicente, 2009: 41).

En 1941 se creó el Consejo Central de Emigración (CCE) que pasaba a sustituir a la Junta Central de Emigración. Su misión era reunir una vez por semana a los representantes de los ministerios con asuntos relativos a la problemática migratoria. Las Juntas Locales y los Patronatos de españoles emigrados fueron mantenidos. Estos últimos, localizados en las colonias importantes de españoles en el extranjero, debían proteger a los emigrados en los planos cultural, físico y socioeconómico. Durante el primer franquismo fueron utilizados por el MOAS para adherir a la causa franquista a los emigrados, hecho que no gustó a los agentes del Ministerio de Asuntos Exteriores y que propició el fracaso de este organismo. "Las luchas entre ambos ministerios y la desconfianza de la colonia española ante cualquier forma de injerencia de las autoridades peninsulares en sus asuntos fueron algunos de los elementos que explican dicho fracaso" (Fernández Vicente, 2009: 41-42).

El 6 de abril de 1943 se promulgó otro Decreto referente a la emigración, mediante el cual se aprobó el llamado Reglamento provisional para el Reclutamiento y Reemplazo del Ejército, donde se establecía que no podrían emigrar: los reclutas en caja, los soldados en situación de servicio en filas, los soldados incluidos en alistamiento anual, los soldados separados temporalmente por inutilidad física y los que tuvieran prórroga de incorporación a filas por ser el sostén de la familia. Además, los jóvenes que quisieran emigrar antes de ser incluidos en alistamiento, tenían que realizar un depósito cuya cuantía aumentaba según se fuera acercando la edad de alistamiento (Fernández Morales, 1992: 234-235).

El Estado franquista encomendó al Ministerio de Trabajo la elaboración de una normativa sobre el tema migratorio. El resultado fue una política migratoria de continuidad, que se tradujo en la Orden Ministerial de 29 de marzo de 1946, por la que quedaba restablecida la Ley y Reglamento de Migración del 20 de diciembre de 1924. Una Ley que no había llegado a ser derogada, pero que tuvo una aplicación muy restringida en los años de las guerras civil y mundial, siendo sustituida en muchas ocasiones por medidas excepcionales. En dicha ley, como 
ya vimos, se proclamaba "la libertad de todo español para emigrar", y se otorgaba la consideración de emigrante a "los españoles o sus familias que, por causa de trabajo abandonasen el territorio nacional para establecerse fuera de él definitiva o temporalmente". En realidad, esta predisposición del Gobierno español no era más que una consecuencia lógica de la situación económica interna incapaz de absorber el excedente de mano de obra rural, que no siempre encontraba acomodo en los núcleos urbanos (Gambi Giménez, 2012: 67-68).

De todas formas, el Gobierno mantenía los objetivos de no fomentar de forma explícita la emigración y, ya que era imposible frenarla, pensaba que era necesario dirigirla y encauzarla de acuerdo a los excedentes de mano de obra en el mercado nacional. De esta forma, el dirigismo llevó a los emigrantes a los países donde mejor se iban a adaptar: América Latina. Alí trataría de ayudarlos en caso de que existiese algún tipo de restricción y a su vez compensaría a los países receptores (Kreienbrink, 2009: 17-18).

La política dirigista de la emigración no tuvo el éxito esperado. El Ministerio de Trabajo terminó ocupándose de la protección de los emigrantes y se inició una política migratoria más aperturista que se plasmó en diversas medidas destinadas a facilitar la emigración, destacando:

- Mayor facilidad para obtener el pasaporte: a partir de 1948, la Dirección General de Seguridad exigió como únicos requisitos la presentación de una carta de llamada o de un contrato de trabajo visado por un consulado español.

- Orden de 5 de enero de 1948 que permitió la libre salida de divisas del país.

- Firma de convenios bilaterales con países latinoamericanos en los que hay mención expresa al problema de la emigración.

- Creación en 1956 del IEE como instrumento destinado a planificar y controlar la emigración, además de asistir, orientar y facilitar transporte más barato y la documentación necesaria.

- Adhesión en 1956 al CIME, al que ya pertenecían países latinoamericanos como: Argentina, Brasil, Colombia, Costa Rica, Chile, Paraguay, Uruguay y Venezuela (Palazón, 1995a: 285).

Finalizada la Segunda Guerra Mundial, España se vio aislada. El único modo que vislumbró el Estado en estos años de ostracismo internacional para mejorar su imagen fue el vínculo con los países latinoamericanos: el espíritu de la Hispanidad. La emigración debía colaborar en la unión de los países hispanos, pero este argumento fue rechazado por la mayor parte de los países sudamericanos. El país que mantuvo relaciones comerciales con España durante estos años fue Argentina, con quien se firmó en 1948 un tratado sobre emigración que nunca fue ratificado, debido al debilitamiento en las relaciones entre ambos países (Kreienbrink, 2009: 18-19). 
España quería y necesitaba que se iniciase el proceso de apertura internacional del Régimen -condenado al aislamiento desde 1946-, para lo que comenzó a formar parte de organismos internacionales como la OMS en 1951 y la UNESCO en 1952. Otro de estos organismos era el Comité Intergubernamental para las Migraciones Europeas (CIME), fundado en 1951 para tratar de resolver los problemas de superpoblación que afectaban a Europa después de la guerra, trasladando a los refugiados y a los emigrantes a otros países. El gobierno franquista vio en esta institución la oportunidad de gestionar el traslado de los emigrantes españoles hacia América Latina, además de mejorar las relaciones exteriores tras el rechazo internacional.

Los orígenes del CIME se remontan a la creación de la Organización Internacional de los Refugiados (OIR) en 1946, gracias al acuerdo de los países vencedores de la guerra para solucionar el problema de los refugiados y desplazados tras el conflicto. Su ejercicio estaba previsto hasta 1950 (Redondo Carrero, 2014: 4), cuando debía crearse otra estructura internacional que se ocuparía del problema. Así, en diciembre de ese mismo año se fundó el Alto Comisionado de las Naciones Unidas para los Refugiados (ACNUR). Su objetivo era asistir a los refugiados, con lo que quedaban fuera de su protección tanto los desplazados como los emigrantes.

Debido a este problema y a la superpoblación que existía en Europa, se empezó a plantear de forma seria el traslado de población. En Europa no había recursos suficientes y los niveles de desempleo eran muy altos, por lo que la mejor solución era apoyar el tránsito de la población excedente hacia Latinoamérica, donde la mayoría de los países necesitaban mano de obra para afrontar su reciente proceso de desarrollo. Así, la Organización Internacional del Trabajo (OIT) celebró una reunión en Bruselas en la que se estableció la creación del Comité Intergubernamental Provisional para los Movimientos Migratorios de Europa (CIPMME), posteriormente conocido como CIME.

Las negociaciones para que España formara parte del CIME comenzaron en 1952 -con el apoyo de países como Argentina, Venezuela o Colombia (Redondo Carrero, 2014: 15)-, pero no fue hasta 1956 cuando se produjo su entrada. Esta supuso un acercamiento con las potencias internacionales después del aislamiento, además de numerosas ventajas relacionadas con el tema migratorio. El régimen se vio apoyado para llevar a cabo la salida de miles de emigrantes a través de los nuevos programas de reagrupación familiar, sin olvidar el beneficio económico que esto supondría para el gobierno y las compañías navieras nacionales.

Tras la incorporación, el acuerdo alcanzado con el CIME preveía trasladar a 10.000 emigrantes españoles durante los primeros años de actuación; los principales destinos serían Venezuela, Argentina, Brasil y Uruguay y tendrían preferencia para el transporte las compañías españolas. Los precios de los pasajes -siempre en pesetas- serían acordados entre las navieras y el CIME, pero 
sin superar los ya establecidos por el gobierno, siendo estos tramitados por el Instituto Español de Moneda Extranjera (Redondo Carrero, 2014: 19).

En España, la conexión con el CIME se realizó a través del Ministerio de Asuntos Exteriores gracias a la Dirección de Emigración y Asuntos Sociales, y a través del Ministerio de Trabajo con el Instituto Español de Emigración. El IEE concertaba con el CIME las travesías dirigidas a otro país miembro y delegaba en la Comisión Católica Española de Migración (CCEM) la organización de todos los programas para la reagrupación familiar.

A Madrí tuven que facer o visado, oh!... Había cónsul (na Coruña) pero...daquela época [1962] como palí estaba eso serrado da amighrasión... sólo iban aqueles que iban pola Emighrasión Católica e tiña que ir faser o visado a Madrí... Papel ao cura tuven que pedirllo pa marchare... (...) de bautismo, que a de nasimento dana no auntamiento. Sólo tuven que buscar eso... (...) E paghei a mitá do pasaghe cando fun pa aló, bueno paghoume meu irmán daló mitá do pasaghe e [a outra] mitá do pasaghe quedou sin paghare (...) (H 277).

En mayo de 1956 comenzó su andadura el CIME en España. El programa de reagrupación familiar -siempre en colaboración con la CCEM- fue el que más éxito tuvo, pero no fue el único. Desarrollaron también programas: de préstamos de viaje; de emigración de obreros rurales e industriales; y de envío de mano de obra a Australia. Durante estos años, y hasta finales de 1960, fueron 43.950 los emigrantes nacionales que se valieron de este servicio. Hacia Latinoamérica fueron 42.822 los españoles trasladados en este lapso de tiempo, destacando por encima de los tradicionales destinos, Brasil y Venezuela. En cifras totales, la irrupción del CIME en el proceso migratorio fue muy importante, ya que en los años comprendidos entre 1956-1960 trasladó a 45.127 personas de un total de 225.953 (Redondo Carrero, 2014: 21-23).

La creación del IEE en 1956 se sumó a la entrada de España en el CIME para canalizar los flujos migratorios y asistir a los emigrantes. Su principal tarea la desarrolló en la posterior emigración española a Europa, ya que los tradicionales destinos americanos se colapsaron debido al aumento de la mano de obra autóctona y foránea, a la crisis económica y a la preferencia ahora de una emigración menor y más cualificada.

Entre los años 1959-1967 los países que más españoles acogieron fueron Venezuela $(42,29 \%)$, Argentina $(25,71 \%)$ y Brasil $(17,93 \%)$, quedando muy por detrás Uruguay $(5,69 \%)$, Colombia $(2,18 \%)$ y México $(1,88 \%)$. Las cifras de emigrantes en los países americanos se fueron reduciendo paulatinamente, pasando del 1.260 .000 españoles en 1960 a 1.000 .000 sólo 10 años después. La población española se concentraba en seis repúblicas, a la cabeza de las cuales continuaba estando Argentina (540.000 personas), seguida de Venezuela (149.747), Brasil (115.893), Cuba (74.026), Uruguay (44.831) y México (31.038) (Fernández Vicente y Kreienbrink, 2009: 231-232). Durante los años setenta y principios de los ochenta las migraciones hacia América siguieron descendiendo 
y Venezuela siguió siendo en la década de los setenta el país preferido por los que todavía emigraban a estos destinos tradicionales.

La política migratoria desarrollada por el IEE atendía no sólo lo referente a América, sino también a la pujante emigración europea. Las características de ambas eran totalmente diferentes y desde la administración se prefirió favorecer la emigración continental en detrimento de la ultramarina, aunque siguieron realizándose todos los programas de asistencia y reagrupación familiar con la ayuda del CIME y la CCEMํ.

(...) Era bueno ir por el Instituto Nacional de Emigración, porque ya uno iba de aquí [Galicia] en regla con todo y bueno, ya uno llegaba allí y ya casi tenía derechos como los venezolanos. El que iba como transeúnte, claro, tenía que (ir a) una agencia, pagar algo, arreglar los papeles, pero era fácil todavía, era muy fácil... (EA 16: Cuquejo).

La unión del CIME y el IEE repercutió en una relación mutua de ayuda en el traslado de emigrantes favoreciendo, por una parte, la presencia de españoles en América e incentivando, por otra, el uso de las navieras españolas para el traslado de pasajeros.

Consigues la condición de emigrante, porque la condición de emigrante te permite salir del país digamos avalado legalmente solicitando en el Instituto Nacional de Emigración que expide como un certificado de, que allí como emigrante te permitía entrar en el país y conseguir trabajo en el caso de Venezuela. Como una emigración legal avalada por el propio Estado español, porque el gobierno español decía este señor sale de aquí porque tiene que irse, y entonces con ese permiso y una autorización del Consulado Venezolano más un permiso de la policía y certificados médicos era lo que solicitábamos (H 1141).

\section{La emigración Gallega entre 1945 y 1960. Causas y Consecuencias}

La emigración es un hecho que está presente a lo largo de la historia de Galicia desde tiempos remotos. Sin embargo, no tiene siempre las mismas características y muestra modalidades diferentes a lo largo de su desarrollo, respondiendo casi siempre a causas vinculadas con las necesidades de la política, el desequilibrio demográfico o las crisis económicas.

Después del periodo de emigración masiva que caracterizó el intervalo comprendido entre 1870 y 1930, cuando aproximadamente un millón doscientos mil gallegos abandonaron su tierra, los años de la II República se caracterizaron

\footnotetext{
3 “O meu foi de 3.165 pesetas por Acción Católica... A revisión médica fun a Madrid e do resto más nada, fun a Lugo e a Madrid... e más nada, porque iba recomendada por o señor cura e onde non movía il, non movia nadie naquil tempo, as cousas son como son... Fumos a Madrid e total que fun a reconocimiento de 3 médicos en Madrid en un día arreglamos todo" (EA 43).
} 
por el retorno de muchos de los españoles instalados en las repúblicas latinoamericanas. En 1935 se aprecia un aumento del número de salidas y el saldo migratorio vuelve a ser positivo ese año. A partir del año siguiente, la Guerra Civil (1936-1939) provoca una nueva onda de salida, pero con características muy diferentes. Se trata de exiliados que huyen del país para salvar la vida. Forman un grupo reducido pero altamente cualificado: artistas, intelectuales, líderes sindicales y políticos, científicos, profesionales, enseñantes etc. Su presencia en América lleva consigo el resurgir de la cultura gallega en la emigración, que tiene como marco fundamental la ciudad de Buenos Aires, pero que se manifiesta también en Montevideo, México, La Habana, Sao Paulo, Salvador de Bahía, Nueva York o Caracas.

Tras la Guerra Civil, el proceso de modernización de la agricultura gallega iniciado a finales del siglo XIX se estanca, ya que el franquismo no soluciona ninguno de los graves problemas endémicos del país. Más bien los agrava (Sixirei, 1988: 134). El programa autárquico impulsado por el nuevo régimen se mostró negativo en todos los frentes y generó progresivamente un incremento del paro, de la inflación, una balanza de pagos negativa, etc. Este “ideal autárquico" permaneció, a pesar de su temprana incapacidad para mejorar la situación económica, hasta finales de la década de los cincuenta, cuando la situación obligó a adoptar medidas estabilizadoras y liberadoras que se recogen en el llamado Plan de Estabilización de 1959, cuyo objetivo estaba en captar divisas para las arcas estatales a través de dos vías: el turismo y la emigración (Fernández Prieto, 2007a: 40).

Las décadas de 1940 y 1950 pueden considerarse las peores de la historia económica y social del siglo XX, marcando una importante regresión técnica y productiva 4 . Galicia sufrió un periodo de contracción de su economía, con el estancamiento del sector agro-ganadero y de las iniciativas agroindustriales originadas en los años veinte y treinta y lo mismo sucedió con los sectores pesquero, conservero y de construcción naval, mientras que los cambios o mejoras, con la excepción del sector hidroeléctrico, fueron reducidos (Fernández Prieto, 2007b: 42).

La principal consecuencia de la política intervencionista del régimen fue la aparición de un mercado negro de productos agrarios (y de otros muchos) al que recurrieron los diferentes estratos de la sociedad rural gallega. Estraperlo, contrabando y mercado negro fueron un recurso habitual de supervivencia. Lo

\footnotetext{
4 Son años de dificultades de abastecimiento y escasez de combustible, recambios, fertilizantes y otros bienes. Se produce una caída de todos los índices de productividad agraria. El trigo y la vid no recuperan hasta 1954 los rendimientos que tuvieran en los años treinta y hasta después de 1959 las patatas y el centeno (Fernández Prieto, 2007b: 80).
} 


\section{que no impidió que el racionamiento ${ }^{5}$ y la escasez continuaran siendo el elemento predominante en el campo:}

(...) en el año cuarenta y cuatro... pues la vida era bastante..., bastante dificililla, dificililla, estaba prácticamente terminando la, las guerras europeas, hacía poco terminara la española, las cosas estaban todas racionadas, en estas aldeas pues, la ración, no nos afectaba mayormente en cuanto a la comida, porque lo de comer diariamente se cultivaba, pero ¿Qué era, en qué consistía la comida? Pues, en..., en caldo hecho con patatas, habas, verduras, un pedacito de carne de cerdo, que se había matao en la casa y pan, de maíz, el pan de trigo era solo para las fiestas, solo en las fiestas, y para eso si había racionamiento, o sea que no, el pan de trigo no se compraba así, todo lo que había que comprar tenía que ser bajo, con una libreta de racionamiento, ehhh..., los que fumaban, me acuerdo, la gente que fumaba, cuando yo era niño, pues tenían un racionamiento, le daban X cantidad de tabaco y los que no fumaban, pues por supuesto, se lo cedían a los amigos que fumaban y después había otras cosas que, que venían en racionamiento que a la gente allí no nos afectaba mayormente, por ejemplo, habas, cosas de esas, pues se cultivaban, no hacían falta. Pero, pero si, el pan si era ya importante, el aceite daban una cantidad, no recuerdo bien, pero creo que era aproximadamente, creo que era medio litro o algo así, por persona y por mes, algo así era, no era mucho más. Y bueno, pero tampoco se utilizaba mucho, porque se utilizaban grasas de cerdo, era..., lo fundamental era el cerdo, eso en cuanto a la comida... en casa pues a lo mejor ibas a vender un poquito de maíz o un poquito de centeno, y con eso, pues a lo mejor traías unos zapatos para el niño... (H 1107).

\section{Y también en las ciudades, como relata este vecino de A Coruña:}

... eran los años 50 y tantos. De aquella, pues había mucha miseria y había... los sueldos eran mínimos y aquí en la fábrica de armas cobraban, no sé, 11 o 12 pesetas al día y se vivía muy mal $^{6}$. O sea que había muchos realquilados. En un piso a lo mejor tenían dos o tres realquilados y se vivía mal, había hambre... (H 1214).

Demográficamente, en la segunda mitad del siglo XX Galicia continua siendo un país de emigrantes pobres, que siguen saliendo por el mundo después de cien años de emigración continuada. Económicamente, es el país del atraso agrario, incapaz de generar un proceso de industrialización sostenido y caracterizado por un desequilibrio creciente entre la economía española y la gallega (Fernández Prieto, 2007a: 12-13).

\footnotetext{
${ }^{5}$ Durante el periodo de racionamiento (1939-1953) los ayuntamientos eran los responsables de la gestión de las cartillas. Las raciones eran del todo insuficientes para cubrir las necesidades alimenticias de la población, a la que no quedaba más remedio que recurrir al mercado negro, en la medida de sus posibilidades, para asegurar la subsistencia.

${ }^{6}$ Los salarios no recuperaron los niveles de 1936 hasta la segunda mitad de los años cincuenta, que se caracterizó por una fuerte inflación de manera que el subconsumo de posguerra no se superó realmente hasta los años sesenta. (...) La coincidencia temporal de esta caída brutal de los salarios con el desabastecimiento autárquico y con el mercado negro, socializó la "fame neghra" desde el comienzo de los años cuarenta (Soutelo Vázquez, 2001: 8).
} 
(...) aos quince anos morreu meu pai, o irmán máis vello estaba na guerra e alí morreu. Nós vivíamos da labranza, e entre...entre miña nai, eu de quince anos e unha irmá de once, tiñamos que labrar a terra para poder comer, eu...eu no tempo da guerra por iso eu...eu quería aprender un oficio, pero non puiden. $\mathrm{O}$ ambiente naquela época era de pobreza, nin había diñeiro, nin había nin roupa para comprar (H 1096).

El ritmo de desagrarización, que era muy fuerte en los años previos a la guerra civil, se interrumpe entre 1936 y 1960. Por cada cien hombres que trabajaban la tierra en 1900, había 80 en 1930, pero 87 en 19507. En este último año, todavía el $78,6 \%$ de la población vivía en el campo (Cuadro 1), proporción que no tenía parangón en ninguna otra parte de España o de Europa.

Cuadro 1. Población urbana y rural de Galicia: 1900-1991

\begin{tabular}{|l|r|r|r|}
\hline AÑOS & POBLACIÓN URBANA & POBLACIÓN RURAL & POBLACIÓN TOTAL \\
\hline 1900 & 9,9 & 90,1 & 1.980 .515 \\
\hline 1910 & 11,4 & 88,6 & 2.063 .589 \\
\hline 1920 & 12,7 & 87,3 & 2.124 .244 \\
\hline 1930 & 13,3 & 86,7 & 2.230 .281 \\
\hline 1940 & 17,8 & 82,2 & 2.495 .860 \\
\hline 1950 & 21,4 & 78,6 & 2.604 .200 \\
\hline 1960 & 24,1 & 75,9 & 2.602 .962 \\
\hline 1970 & 28,5 & 71,5 & 2.583 .674 \\
\hline 1981 & 33,2 & 66,8 & 2.753 .836 \\
\hline 1991 & 36,5 & 63,5 & 2.720 .445 \\
\hline
\end{tabular}

Fuente: Censos de Población, I.N.E.

Por cada 100 hectáreas de terreno cultivado había en Galicia 353 personas, mientras que Asturias, en la misma época, tenía 182.

Se había algún veciño que daba alguna terra a traballar pois igual estábamos catro ou cinco esperando de collela... estaban todas as casas cheíñas de xente e dispois no era decir ocupadas por o pai e un fillo solo... todos éramos a seis como che conto e a cinco, e a cuatro... salvo unha excepción de que algún aprendía un oficio, pero o campo era o de todos (H 317).

El país se presentaba como un vivero afanoso de pequeños propietarios: poca tierra para mucha gente (Sixirei, 2001). “Non había traballo, había miseria, había que traballar nas terras e as terras non daban nada... eramos moitos a traballar e eramos moita xente e non había traballo, era moita miseria" (H 311).

\footnotetext{
7 Paz Andrade utiliza datos del Censo de 1950, en ese año Galicia contaba con una población económicamente activa de: 1.152 .584 personas, de las que tan solo 147.573 (12,8\%) desempeñaban su actividad en un medio urbano y $1.005 .011(87,2 \%)$ en zona rural. Con respecto al sexo, en el campo 722.076 son varones y 282.935 son mujeres, mientras que en el medio urbano 108.710 son varones y 38.863 son mujeres (Paz Andrade, 1959: 62).
} 
Lo más cotidiano en el campo gallego era “(...) rozar toxos, coller esterco, patacas, maíz, cuidar vaquiñas e vender o leite" (H 496). Pero también, desde muy joven, había que aprovechar otros recursos que el medio proporcionara:

(...) antes de emigrar, [a situación en Galicia era] mala porque comíase algo do que producía o campo; se había unha mala cosecha, había, se pode decir fame, algo de fame durante o ano... eu teño traballao moito... na aldea miña había unha isliña que de inverno, cando cresía o río había moitas arenas, moita arena, e eu po hospital [de Santiago en construcción] quitei, moito, varios sentos de metros cúbicos. De rapás, tendo poucos anos metiamonos desnudos no río, cheos de frio, e eramos varios rapases da aldea, e despois xuntabamos camións [de área] e viña un camión que era... vello, que era o único que cargaba oito ou des toneladas, que daquela non había camións. E eu contribuín moito a construir o hospital... Cando enchía o rio aproveitabamos pa janar un peso, pa axudar na casa e máis, eramos rapases e, coma quen dí, pa comer un caramelo ou unhas jalletas, que outra cousa non se aspiraba (H 1039).

Según los datos del Catastro de Rústica correspondientes a 1954, Galicia tenía la menor extensión media de tierra por propietario de España (3,55 ha), el mayor número de parcelas por propietario $(16,59)$ y la menor superficie de las mismas (0,21 ha). (Míguez, 1967: 73). Se trata de un minifundio "desesperante" con 530.000 hectáreas cultivadas, divididas en 15 millones de parcelas, lo que es indicador de un país de "miserable" economía agraria, donde el gallego es “habitante pobre de una tierra rica” (Núñez Búa, 15/10/1967). Galicia, a su vez, aparecía con la menor renta imponible por contribuyente $(627,47)$, lo que no impidió que, entre 1945 y 1957, el país sufriera el mayor porcentaje de incremento tributario sobre la propiedad de toda España (un 300\%) (Sixirei, 2001).

La tierra, como señalaba un informe del Banco de La Coruña de 1958, seguía trabajada con métodos e instrumentos primitivos: "Todavía existen en Galicia unos 400.000 arados romanos" (Banco de La Coruña, 1958) y los tractores y maquinaria de tracción a motor eran prácticamente desconocidos. A base de esfuerzo humano y animal, la agricultura gallega tenía simultáneamente en la década de los cincuenta la mayor productividad de España en pesetas por hectárea y la menor productividad en pesetas por persona. La renta per cápita del campesino gallego no superaba, en esa década, las 4.000 Pts./año. Había casos en los que no daba ni para comprar cerillas: “(...) se vivía en unha situación enorme e precaria, inda cando había que prender o lume... antes neste tempo cando había moita xeada había que che salir cunha piña en busca do lume ás casas de afora, porque había quen tiña un misto e había quen non o tiña..." (H 318).

A partir de 1950, se produce una expansión del sector eléctrico en Galicia. Se construyen grandes embalses en los ríos Miño y Sil, lo que permite un aumento espectacular en la producción de energía eléctrica, explotada casi en régimen de monopolio por FENOSA, empresa fundada en 1945 con capital procedente de la emigración. Curiosamente, en 1958 había en Galicia 700.000 
personas sin luz eléctrica en sus casas, a pesar de que el país no solo exportaba energía sino que era, después de Cataluña, el mayor productor de España. La provincia de Santander superaba en consumo eléctrico a las cuatro provincias gallegas juntas; 83 municipios gallegos carecían de tendidos eléctricos y paradójicamente estaban casi todos en Lugo y Ourense, las provincias con mayor producción de energía hidroeléctrica. En relación con la renta per cápita, las provincias gallegas ocupaban, entre las 50 provincias españolas, los puestos 30 (Coruña), 31 (Pontevedra), 42 (Lugo) y 49 (Ourense) (Paz Andrade, 1959).

Otro ramo con una actividad destacada en este periodo fue el de la minería con la explotación del wolframio, que había tenido un desarrollo limitado entre 1905 y 1935, pero que, debido a su carácter estratégico, será de gran importancia en esta etapa caracterizada por dos grandes conflictos bélicos: la II Guerra mundial y la Guerra de Corea. En 1943 hay 90 explotaciones legales que ocupan a 10.000 trabajadores (Alonso Fernández, 1997: 344).

Se produce también un pequeño auge del sector servicios, sobre todo en las provincias de A Coruña y Pontevedra. Continúa, además, el relativo proceso de industrialización iniciado en la segunda década del siglo XX, centrado sobre todo en la pesca y la conserva, en la metalurgia y en la industria maderera.

Según X. M. Beiras (1984), con la casi absoluta excepción de la industria conservera y de la pesca llamada industrial, en Galicia no existen unidades de producción y de envergadura capitalista hasta la década siguiente a la guerra civil española. "E mesmo a conserva e a pesca industrial carecen internamente da dimensión empresarial e globalmente da potencia económica precisas pra faceren sentir o seu peso específico nas instancias gubernamentais do Estado..." (Beiras, 1984: 21).

La pesca y el sector conservero emplean ya en 1930 al $11 \%$ de la población activa gallega y constituyen el "único núcleo productivo estructurado de la economía gallega", que va a experimentar un fuerte proceso de expansión a partir de la década de 1960 encabezado por Pescanova. La metalurgia, vinculada al mundo del mar, abarca desde los grandes astilleros hasta los más pequeños, las fundiciones o las fábricas de construcción de maquinaria ligera (Alonso Fernández, 1997: 342).

Un aspecto destacable entre 1940 y 1960 fue la progresiva transformación y explotación de los montes con la introducción de especies de crecimiento rápido, lo que va unido a una rápida expansión de la industria de la madera, inicialmente limitada a aserraderos, pero muy pronto ampliada a fábricas de aglomerados y tableros, así como de celulosa.

Sin embargo, las transformaciones que experimentó la economía gallega en la década de los 60 no afectaron en profundidad al campo, que debió esperar al decenio siguiente para iniciar un franco proceso de modernización, basado en la transformación de sus infraestructuras mediante el proceso de concentración 
parcelaria y la mecanización de las labores agrícolas. Si en 1960 había 700.000 personas trabajando en la agricultura, en 1973 eran todavía 651.000, lo que representaba el $52 \%$ del total de la población activa del país. No sorprende por tanto, que se levantasen voces criticando la marginación de Galicia y reivindicando la necesidad de que los poderes públicos promovieran su desarrollo económico: "La región que no pide ni crea problemas; la tierra sumisa que todo lo ha dado al país; (...) esta tierra marginada y alejada del corazón de la Península, necesita que, de un modo decisivo, se fijen en ella los poderes públicos" (Moure-Mariño, 11/08/1968).

La escasez de empleo industrial, el raquitismo de los servicios y la alta densidad de población rural configuraron un espacio económico en el que Galicia asumía el papel de suministradora de mano de obra, de energía y de materias primas, además de recursos financieros a través del ahorro y de las remesas de emigrantes ${ }^{8}$.

No es de extrañar que en este contexto de subdesarrollo y sin alternativas viables a corto y medio plazo, volviera a abrirse la espita de la emigración ${ }^{9}$. La corriente migratoria hacia América se reanuda con inusitada fuerza entre 1947 y 1960, alcanzando cifras similares a las del primer tercio de siglo, sobre todo entre los años 1949 y 1958.

Bueno eiquí non estaba moi ben porque se non xa non... xa non marchabamos, ¿non? De paso que tiñamos algo de terra pois íbamos comendo e bebendo algo, vamos en fin... e por ejemplo había unas vacas e tiña cousas desas, pois iba un... un vivindo, ¿non?, vivindo malamente, e entonces despois como viñeron estas "américas", por ejemplo, Venezuela... pois tratamos de... de emigrar (H 313).

Entre 1946 y 1960, de un total de 634.604 españoles que emigraron a América, Galicia ${ }^{10}$ suministró ella sola casi la mitad: 292.399 emigrantes, cifra que alcanza el $46 \%$ del total de la emigración española. Por provincias, la emigración gallega transoceánica se repartió de la siguiente manera: Pontevedra: 95.038 (representa el $32,50 \%$ del total gallego y el $14,97 \%$ sobre el total de España); A Coruña: 94.661 (32,37\% y 14,91\%); Ourense: 64.587 (22,08\% y $10,17 \%)$ y Lugo: $41.995(15,7 \%$ y 7,25\%). Sólo dos provincias gallegas, A Coruña y Pontevedra aportan el $30 \%$ de la emigración española a ultramar (Cuadro 3).

\footnotetext{
${ }^{8}$ El economista Antonio Taboada (30/11/1969), Secretario General de la Cámara de Comercio de A Coruña, en 1969, afirmaba que Galicia aportaba a la economía española: el $40 \%$ de las remesas de emigrantes, el $29 \%$ de las carnes de vacuno, el $19 \%$ de la madera, el $34 \%$ de pescados y mariscos, el $40 \%$ de conservas, el $50 \%$ de construcciones navales y el $15 \%$ de energía eléctrica.

9 Según el Instituto Nacional de Emigración entre 1941 y 1950 abandonaron Galicia 115.359 personas (271.890 para toda España), lo que retrotraía las cifras a los años veinte.

10 Salvador Palazón indica que Galicia entre 1946 y 1958 tiene unos índices medios anuales en torno a los 75 emigrantes transoceánicos por cada diez mil habitantes censados en 1950 (Palazón, 1995a: 298).
} 
Cuadro 3. Emigración gallega a América por provincias: 1946-1970

\begin{tabular}{|l|r|r|r|r|r|r|}
\hline AÑO & A CORUÑA & LUGO & OURENSE & PONTEV. & GALICIA & ESPAÑA \\
\hline 1946 & 520 & 174 & 331 & 655 & 1.680 & 5.575 \\
\hline 1947 & 1.543 & 1.105 & 1.248 & 2.354 & 6.250 & 13.532 \\
\hline 1948 & 2.532 & 2.054 & 1.963 & 3.828 & 10.377 & 19.156 \\
\hline 1949 & 6.030 & 4.080 & 3.975 & 7.025 & 21.110 & 41.910 \\
\hline 1950 & 6.748 & 5.161 & 5.489 & 9.983 & 27.381 & 55.314 \\
\hline 1951 & 7.590 & 4.177 & 4.888 & 8.545 & 25.200 & 56.907 \\
\hline 1952 & 8.441 & 3.197 & 6.381 & 8.051 & 26.070 & 56.648 \\
\hline 1953 & 8.156 & 2.206 & 5.841 & 7.340 & 23.543 & 44.572 \\
\hline 1954 & 7.668 & 2.364 & 6.036 & 6.570 & 22.638 & 52.418 \\
\hline 1955 & 10.998 & 3.323 & 6.792 & 8.380 & 29.493 & 62.237 \\
\hline 1956 & 8.000 & 2.710 & 5.236 & 6.944 & 22.890 & 53.082 \\
\hline 1957 & 9.882 & 2.897 & 5.664 & 8.979 & 27.422 & 57.900 \\
\hline 1958 & 7.443 & 2.240 & 4.253 & 7.018 & 20.954 & 47.179 \\
\hline 1959 & 4.851 & 1.350 & 3.095 & 4.661 & 13.957 & 34.648 \\
\hline 1960 & 4.259 & 1.075 & 3.395 & 4.705 & 13.434 & 33.529 \\
\hline 1961 & 4.086 & 1.217 & 3.190 & 5.369 & 13.862 & 35.658 \\
\hline 1962 & 4.296 & 1.313 & 2.689 & 4.884 & 13.182 & 31.951 \\
\hline 1963 & 3.514 & 847 & 2.513 & 3.996 & 10.870 & 24.416 \\
\hline 1964 & 3.000 & 833 & 2.455 & 3.329 & 9.617 & 23.915 \\
\hline 1965 & 2.696 & 652 & 2.246 & 2.617 & 8.211 & 20.754 \\
\hline 1966 & 2.742 & 676 & 2.083 & 2.501 & 8.002 & 20.710 \\
\hline 1967 & 2.252 & 609 & 2.244 & 2.545 & 7.650 & 18.854 \\
\hline 1968 & 2.180 & 518 & 2.070 & 2.847 & 7.615 & 10.467 \\
\hline 1969 & 2.216 & 627 & 1.667 & 3.373 & 7.883 & 10.129 \\
\hline 1970 & 1.831 & 605 & 1.983 & 2.541 & 6.960 & \\
\hline TOTAL & 123.474 & 46.010 & 87.727 & 129.040 & 386.251 & \\
\hline
\end{tabular}

Fuente: Elaboración propia a partir de Álvarez Silvar (2002: 67).

Entre 1950 y 1965, la población gallega solamente creció en 15.405 habitantes. Poco más de mil habitantes anuales y el motivo, evidentemente, hay que buscarlo en la emigración (Domínguez, 30/04/1968: 6). Una emigración que (continuando con el debate abierto en el siglo XIX entre los partidarios y detractores de la emigración) el escritor y notario Luis Moure-Mariño considera de manera contundente una sangría progresiva:

(...) que, además se lleva hacia afuera lo mejor y más vigoroso de la raza. Los hombres (...) que exportamos van a enriquecer a otros pueblos con su trabajo y su espíritu creador, entretanto Galicia se empobrece progresivamente. (...) Posiblemente las remesas de los emigrantes no bastan para compensar lo que dejan de producir nuestras tierras yermas o la actividad creadora que esos hijos podrían aportar dentro de la tierra nativa; pero, además, la emigración nos devuelve enfermos, tarados y viejos que a última hora, después de su triste odisea, vuelven a dejar su cadáver en la tierra natal (Moure-Mariño, 30/04/1968). 
La emigración a América en estos años 40, 50 y 60 se dirige con preferencia a Argentina y Venezuela, además de Uruguay, Brasil y Cuba en menor medida. Es decir, salvo Venezuela ${ }^{11}$, que a mediados de los años cincuenta se convierte en el objetivo preferente de los gallegos que emigran a América, se trata de los destinos tradicionales a los que cabe añadir algunos nuevos, pero siempre de mucha menor importancia, como Santo Domingo, Puerto Rico, México y Panamá, además, claro está, de Estados Unidos y Canadá.

Esta emigración continuó siendo mayoritariamente masculina pero los porcentajes tienden a acercarse: el $55,9 \%$ eran varones y el $44,1 \%$ mujeres $^{12}$ a lo que hay que añadir que en relación al conjunto de la población, las mujeres emigraron más de Galicia que de cualquier otra parte de España. El perfil del emigrante a América se complementa con los siguientes datos: soltero, tiene entre 15 y 35 años, sabe leer y escribir (porcentaje de alfabetos: el 95,1\%, unas décimas por encima del porcentaje español) y es de origen campesino. Es decir, en líneas generales se mantene el retrato del emigrante correspondiente a décadas anteriores.

A finales de la década de los 50 se produce un cambio de rumbo en la orientación de la emigración gallega y Europa occidental ${ }^{13}$ sustituye a América como destino prioritario hasta los años 70, en que la emigración gallega pierde fuerza. La crisis económica que se extiende por los países europeos a partir de 1973 obliga a muchos trabajadores a regresar, al mismo tiempo que se cierran las puertas para nuevos aportes. La historia de la emigración gallega parecía haber llegado a su fin (Sixirei, 2001). En palabras de X.M. Beiras: “(...) si [ Galicia] no se desangra (...) todavía hoy [1981] en la riada emigratoria, no es merced a ninguna oportuna política económica del Estado, sino pura y simplemente por culpa de la crisis en la que se debaten ahora los habituales países de destino de nuestros emigrantes" (Beiras, 1982: 16).

\footnotetext{
${ }^{11}$ Argentina había de ceder entonces a Venezuela su primacía como país de inserción. El bolívar inflado por el petróleo desplazó al peso enflaquecido por la política en los sueños dorados del emigrante" (Paz Andrade, 1970: 58).

12 Distribución según el sexo de los gallegos emigrados a ultramar por vía marítima, 1946-1964 (185.908 hombres y 146.718 mujeres) (Sánchez López, 1967: 78).

${ }^{13}$ Se estima que entre 1960 y 1975 medio millón de gallegos emigraron a Suiza, Alemania, Francia, Holanda y el Reino Unido, lo que supone el $65 \%$ de todos los que salieron de Galicia entre esos años (Fernández Prieto, 2007a: 38).

Para Valentín Paz Andrade las corrientes migratorias “son como afluentes de lo que ha sido un río. El río ha cambiado de cauce al reducir la emigración gallega su tradicional proclividad americana. Desgraciadamente, sin pérdida del volumen total" (Paz Andrade, 1970: 59)
} 


\section{Referências Bibliográficas}

Alonso Fernández, Bieito. (1997). "Idade Contemporánea. Século XX", en Historia Xeral de Galicia, Vigo, Edicións a Nosa Terra, pp. 333-393.

Álvarez Silvar, Gabriel. (2002). La migración de retorno en Galicia (1970-1995), Universidad Complutense de Madrid, Facultad de Ciencias Políticas y Sociología. Tesis doctoral.

Banco de La Coruña. (1958). Informe sobre la economía gallega. La Coruña.

Beiras, Xosé Manuel. (1982). El atraso económico de Galicia. Vigo, Xerais.

Beiras, Xosé Manuel. (1984). “A conceitualización das categorías de analese para o estudo da estrutura económica galega", en Por unha Galicia liberada. Vigo, Xerais.

Domínguez, M. L. (1968). "Galicia: su población”. Correo de Galicia. Buenos Aires, $30 / 04 / 1968$, p. 6.

EA 16: Saturnino Cuquejo (Baltar, Ourense). Nacido en 1928, emigró a Venezuela en 1957. Fecha entrevista: 28/01/1999.

EA 43: Mujer (Ferreira de Pantón, Lugo). Nacida en 1941, emigró a Venezuela en 1963 y retornó a Galicia en 1992. Fecha entrevista: 23/11/1997.

Entrevistas HISTORGA (Archivo de Historia Oral de Galicia. Facultade de Xeografía e Historia. Universidade de Santiago de Compostela):

Fernández Morales, Má José. (1992). La emigración española a Venezuela de 1850 a 1960. Madrid, Universidad Complutense de Madrid, Facultad de Geografía e Historia. Tesis Doctoral.

Fernández Prieto, Lourenzo. (2007a). “Dinamismo social e desenvolvemento económico", en A gran Historia de Galicia. Século XX. Unha economía: dúas sociedades. A Coruña, t. XIII, vol. I, Edición a Voz de Galicia.

Fernández Prieto, Lourenzo. (2007b). “O franquismo. Atraso económico nunha sociedade destruída", en $A$ gran Historia de Galicia. Século XX. Unha economía: dúas sociedades. A Coruña, t. XIII, vol. II, Edición a Voz de Galicia.

Fernández Vicente, Mạ José. (2009). “La evolución del organigrama migratorio español: el papel del IEE", en Calvo Salgado et. al.: Historia del Instituto Español de Emigración. Madrid, Ministerio de Trabajo e Inmigración, Subdirección General de Información Administrativa y Publicaciones, pp. 35 62. 
Fernández Vicente, Mạ José y Kreienbrink, Axel. (2009). “Las relaciones del IEE con los países de ultramar", en Calvo Salgado et. al.: Historia del Instituto Español de Emigración. Madrid, Ministerio de Trabajo e Inmigración, Subdirección General de Información Administrativa y Publicaciones, pp. 231251.

Gambi Giménez, Esther. (2012). La emigración castellana y leonesa a Brasil, Salamanca. Ed. Universidad de Salamanca. Tesis doctoral.

González-Rothvoss y Gil, Mariano. (1949). Los problemas actuales de la emigración española. Madrid, Instituto de Estudios Políticos.

H 277: Albina Mouro Ameijeiras (Santa Comba, A Coruña). Nacida en 1943, emigró a Venezuela en 1962 y retornó a Galicia en 1973.

H 311: Concepción Mouriño Rodríguez (Celanova, Ourense). Nacida en 1933, emigró a Venezuela en 1979 y retornó a Galicia en 1977.

H 313: Benjamín Enríquez Sousa (Celanova, Ourense). Nacido en 1930, emigró a Venezuela en 1958 y retornó a Galicia en 1969.

H 317: Francisco Pérez Somoza (Celanova, Ourense). Nacido en 1933, emigró a Venezuela en 1957 y retornó a Galicia en 1968.

H 318: Rosa Pérez Salgado (Celanova, Ourense). Nacida en 1933, emigró a Venezuela en 1958.

H 496: Felisindo Trigo Rodríguez (San Simón, Pontevedra). Nacido en 1913, emigró a Venezuela en 1953.

H 1039: Manuel Pedrido Suárez (Santiago de Compostela, A Coruña). Nacido en 1932, emigró a Venezuela en 1956 y retornó a Galicia en 1969.

H 1096: Juan Rey Beje.

H 1107: Elías Rodríguez Regueiro. Nacido en 1944, emigró a Venezuela en 1962 y retornó a Galicia en 1989.

H 1141: Luis Ferreiro (Celanova, Ourense). Emigró a Venezuela en 1967.

H 1214: Antonio Hipólito Purriños Currás (Vilalba, Lugo). Nacido en 1928, emigró a Venezuela en 1956 y retornó a Galicia en 1962.

Kreienbrink, Axel. (2009). "La política de emigración a través de la historia del IEE", en Calvo Salgado et. al.: Historia del Instituto Español de Emigración, Madrid, Ministerio de Trabajo e Inmigración, Subdirección General de Información Administrativa y Publicaciones, pp. 13-33. 
Míguez, Alberto. (1967). Galicia: Éxodo y Desarrollo. Madrid, Ed. Cuadernos para el Diálogo.

Moure-Mariño, Luis. (1968). "El aliviadero de la inmigración", Correo de Galicia. Buenos Aires, 30/04/1968.

Moure-Mariño, Luis. (1968). “Galicia, tierra sumisa..." La Voz de Galicia. A Coruña, 11/08/1968.

Núñez Búa, José.( 1967). "Minifundismo", Correo de Galicia, № 48, Buenos Aires, 15/10/1967.

Palazón, Salvador. (1995a). Capital humano español y desarrollo latinoamericano. Evolución, causas y características del flujo migratorio (1882-1990). Alicante, Institut de Cultura Juan Gil-Albert.

Palazón, Salvador. (1995b). Los españoles en América Latina (1850-1990). Madrid, Fundación Centro Español de Estudios de América Latina (CEDEAL).

Paz Andrade, Valentín. (1959). Galicia como tarea. Buenos Aires, Ediciones Galicia.

Paz Andrade, Valentín. (1970). La marginación de Galicia. Madrid, Siglo XXI.

Redondo Carrero, Emilio. (2014). El gobierno franquista y el ingreso de España en los organismos internacionales: el caso del CIME. Grupo de Estudios Americanos, Consejo Superior de Investigaciones Científicas (CSIC).

Sánchez López, Francisco. (1967). Movimientos migratorios de Galicia. Vigo, Faro de Vigo.

Sixirei Paredes, Carlos. (1988). A emigración. Vigo, Ed. Galaxia.

Sixirei Paredes, Carlos. (2001). "Introducción breve ao fenómeno histórico da emigración galega", en Sixirei, C., Campos, X.R. y Fernández, E.: Asociacionismo Galego no exterior. Santiago de Compostela, Xunta de Galicia, pp. 33-84.

Soutelo Vázquez, Raúl. (2001). "Galicia nos tempos do medo e fame: Autarquía, sociedade e mercado negro no primeiro franquismo, 1936-1959", en Historia 11. Santiago de Compostela, IDEGA, Universidade de Santiago de Compostela.

Taboada Arceo, Antonio.( 1969). "Galicia y el II Plan de Desarrollo", Correo de Galicia, no 98, Buenos Aires, 30/11/1969.

Recebido em 29/07/2014

Aceito 28/10/2014 